\title{
Preparation for Supercomputing of Numerical Simulation of Fracture Process of Composite Materials
}

\author{
Takeaki Nadabe \\ Department of Advanced Energy \\ The University of Tokyo \\ Chiba, Japan \\ e-mail: nadabe@smart.k.u-tokyo.ac.jp
}

\author{
Nobuo Takeda \\ Department of Advanced Energy \\ The University of Tokyo \\ Chiba, Japan \\ e-mail: takeda@smart.k.u-tokyo.ac.jp
}

\begin{abstract}
This study investigates the preparation for supercomputing of numerical simulation of fracture process of composite materials. The purpose of this study is to establish the numerical analysis method to understand the fracture mechanism and predict the mechanical response of composite materials through the supercomputing. The numerical model is constructed for laminated plate of composite material, and the stacking sequence of the simulated laminate is $[0 / 90] \mathrm{s}$ cross-ply laminate. The reinforcement fibers in $\mathbf{0 - d e g r e e}$ plies are modeled by circle cross-section beam elements to represent the threedimensional effect in bending of fibers. Cohesive elements are inserted in the connection of beam elements to simulate the bending breaking of fibers. For the purpose of parallel computing, the domain decomposition method is applied, and for pre-conditioned conjugate gradient algorithm, incomplete Cholesky conjugate gradient method is applied. The simulated results show that in the initial state of the loading, the stress concentration occurs around the initial misalignment of fiber in 0-degree plies, and it also occurs around the area where fibers come close in 90-degree plies. At average applied strain $1.20 \%$, the fiber breaking damage initiates in 0-degree ply, and after this point the damage develops in the material. The simulated damage is close to the microscope picture of the actual composite materials obtained in the experiment. The current simulation is considered to correspond with the actual material deformation.
\end{abstract}

Keywords-numerical simulation; fracture mechanism; strength analysis; composite materials

\section{INTRODUCTION}

Composite materials commonly have complex internal structures including fibers, matrix, interfaces and interlaminar regions, and when precise evaluation of fracture strength of the material is conducted, the internal fracture process in the materials is necessary to be taken into account in the numerical analysis [1-5]. In recent years, the capability of computers has been extensively improved and the fracture mechanism of composite materials including crack propagation, interlaminar delamination and fiber/matrix interface decohesion are simulated using the computational capability [6]. Applying the numerical simulation of fracture process of the material, the detail stress and strain distribution in the inside of the material are considered to be clarified, and several indications for improving the mechanical performance of the material are considered to be obtained [7-9]. This study investigates the preparation for supercomputing of numerical simulation of fracture process of composite materials. The purpose of this study is to establish the numerical analysis method to understand the fracture mechanism and predict the mechanical response of composite materials through the supercomputing.

\section{NUMERICAL MODEL}

The numerical model is constructed for laminated plate of composite material. Fig. 1 illustrates the analysis model. Finite element method is used for the analysis. The stacking sequence of the laminate is [0/90]s cross-ply laminate. The white and gray elements in Fig. 1 represent fibers and matrix, respectively. The thickness of the ply in $\mathrm{y}$-direction is $85 \mu \mathrm{m}$. The length in $\mathrm{x}$-direction is $200 \mu \mathrm{m}$, and the thickness in z-direction is $100 \mathrm{~mm}$. The diameter of each fiber is set to $7.0 \mu \mathrm{m}$, and the interval of fibers is $10.0 \mu \mathrm{m}$. The fiber volume fraction of the materials is set to $40.0 \%$, and there are 9 fibers in each 0-degree ply. In this analysis, in order to simulate the bending breaking of each fiber, the fibers in 0-degree plies are modeled by circle cross-section beam elements, and the cohesive elements are inserted in the connection of fiber beam elements. When the high bending deformation occurs in fiber beam elements, the cohesive elements open and the fiber bending breaking occurs in the analysis. The fiber beam elements applied in this analysis are the Timoshenko type beam elements and have three nodes and four integration points. The matrix in 0-degree plies and the fibers and matrix in 90-degree plies are modeled by twodimensional plate elements. The plate elements have eight nodes and four integration points in order to avoid the shear locking and zero-energy mode deformation particularly in plastic deformation. The one fiber placed at the center in each 0-degree ply has the initial misalignment as shown in Fig. 1. The initial misalignment of the fiber is introduced using the sine function. The $\mathrm{x}$ coordinate of each node is placed regularly, and the y coordinate of each node is calculated using the sine function. Only the central part of this fiber has the misalignment and the other part of the fiber is modeled as the straight line. The other fibers in 0 -degree plies are also modeled as the straight lines and the 


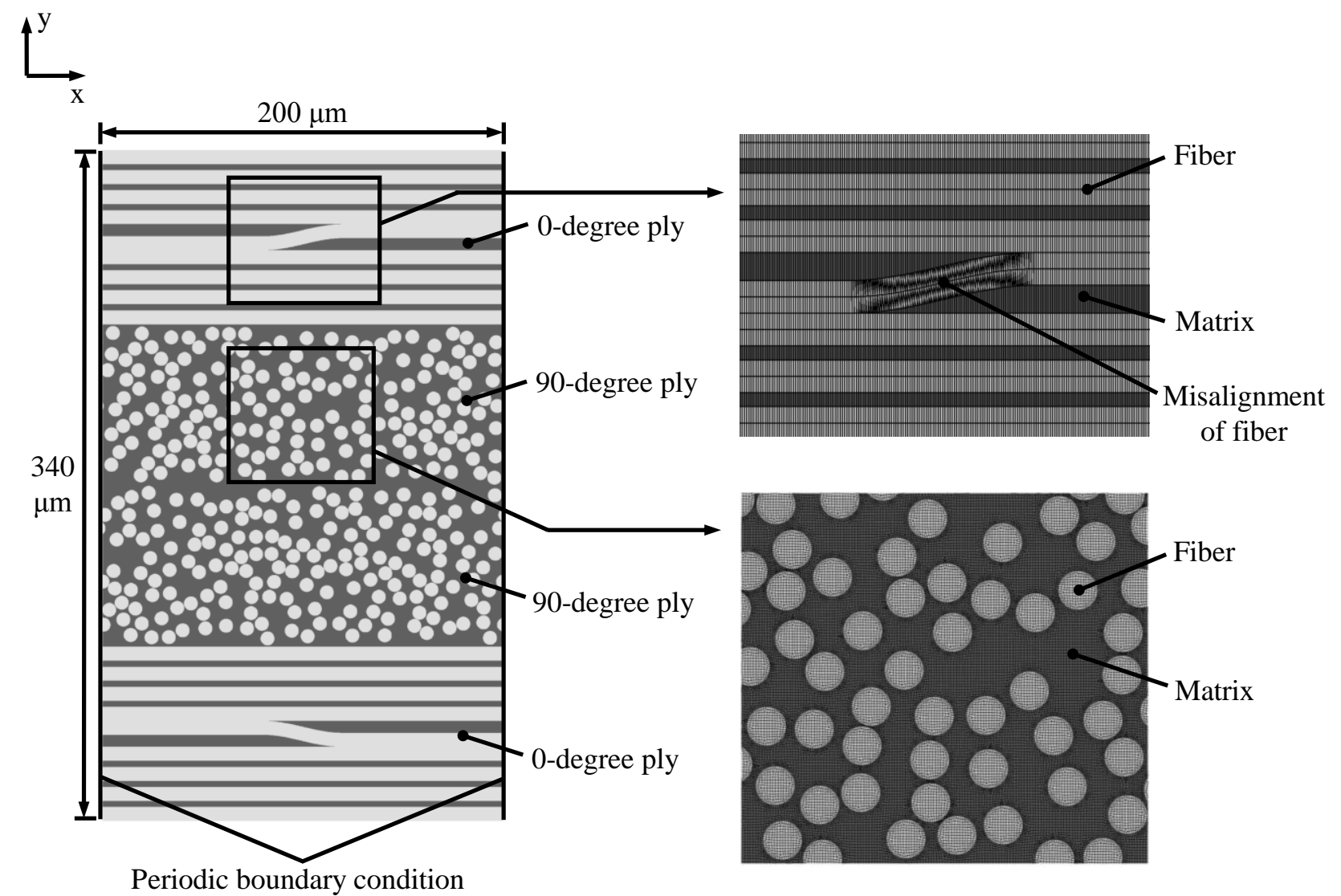

Figure 1. Numerical model of cross-ply laminate.

TABLE I. Material Property of Fiber. CARbon Fiber AS4 (HEXCEL CORP.) IS ASSUMED [10].

\begin{tabular}{|l|c|c|}
\hline $\begin{array}{l}\text { Elastic modulus in fiber axial } \\
\text { direction }\end{array}$ & 225 & $\mathrm{GPa}$ \\
\hline $\begin{array}{l}\text { Elastic modulus in transverse } \\
\text { direction }\end{array}$ & 15 & $\mathrm{GPa}$ \\
\hline In-plane Poisson's ratio & 0.20 & \\
\hline In-plane shear modulus & 15 & $\mathrm{GPa}$ \\
\hline Transverse shear modulus & 7.0 & $\mathrm{GPa}$ \\
\hline
\end{tabular}

TABLE II. MATERIAL PROPERTY OF MATRIX. EPOXY RESIN 35016 (HERCULES CHEMICAL COMPANY, INC.) Is ASSUMED [10].

\begin{tabular}{|l|c|c|}
\hline Elastic modulus & 4.2 & $\mathrm{GPa}$ \\
\hline Poisson's ratio & 0.34 & \\
\hline Yield stress & 90 & $\mathrm{MPa}$ \\
\hline
\end{tabular}

fiber axial direction is parallel to the x-direction. The periodic boundary condition is introduced in both edge of the laminate to avoid the edge fracture of the material.

Due to the atomic structure in the inside of the fibers, the fibers commonly have the different material property in between fiber axial and transverse directions. Here, the fibers are modeled by the transversely isotropic elastic material. Table I shows the material property of the fibers. Carbon fiber AS4 (Hexcel Corp.) is assumed [10]. Matrix is modeled by isotropic elastic-plastic material. Commonly the compressive failure of composite materials is affected

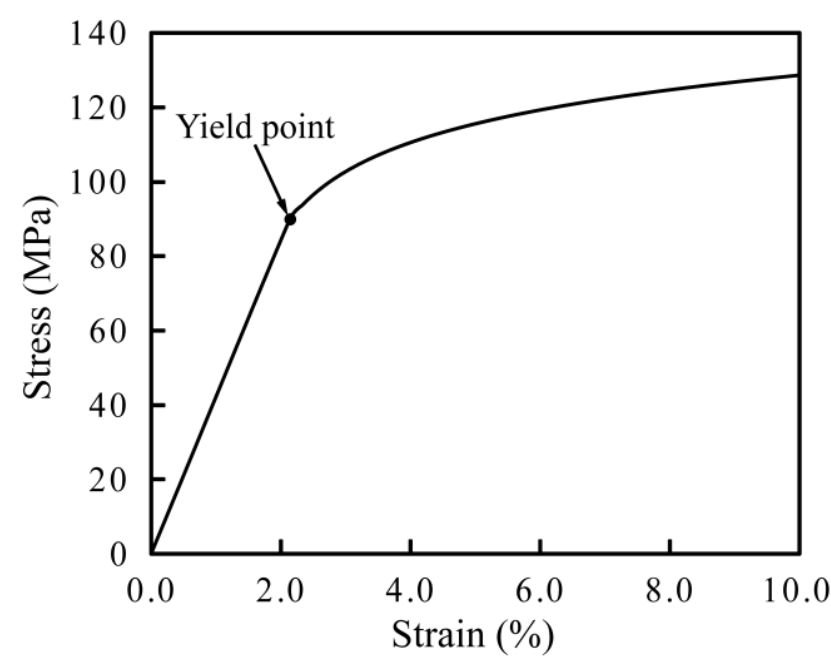

Figure 2. Stress-strain curve of matrix.

by the nonlinear stress-strain relation of matrix, thus in this analysis the nonlinear stress-strain curve of matrix shown in Fig. 2 is applied, and the nonlinear finite element analysis is conducted. Table II shows the material property of matrix. Epoxy resin 3501-6 (Hercules Chemical Company, Inc.) is assumed [10]. The quasi-static and room temperature environment are assumed in the analysis.

Since the geometrical nonlinearity commonly affects the buckling phenomena of the materials, the geometrical nonlinear effect is incorporated in the analysis. The incremental analysis in the finite element analysis is 


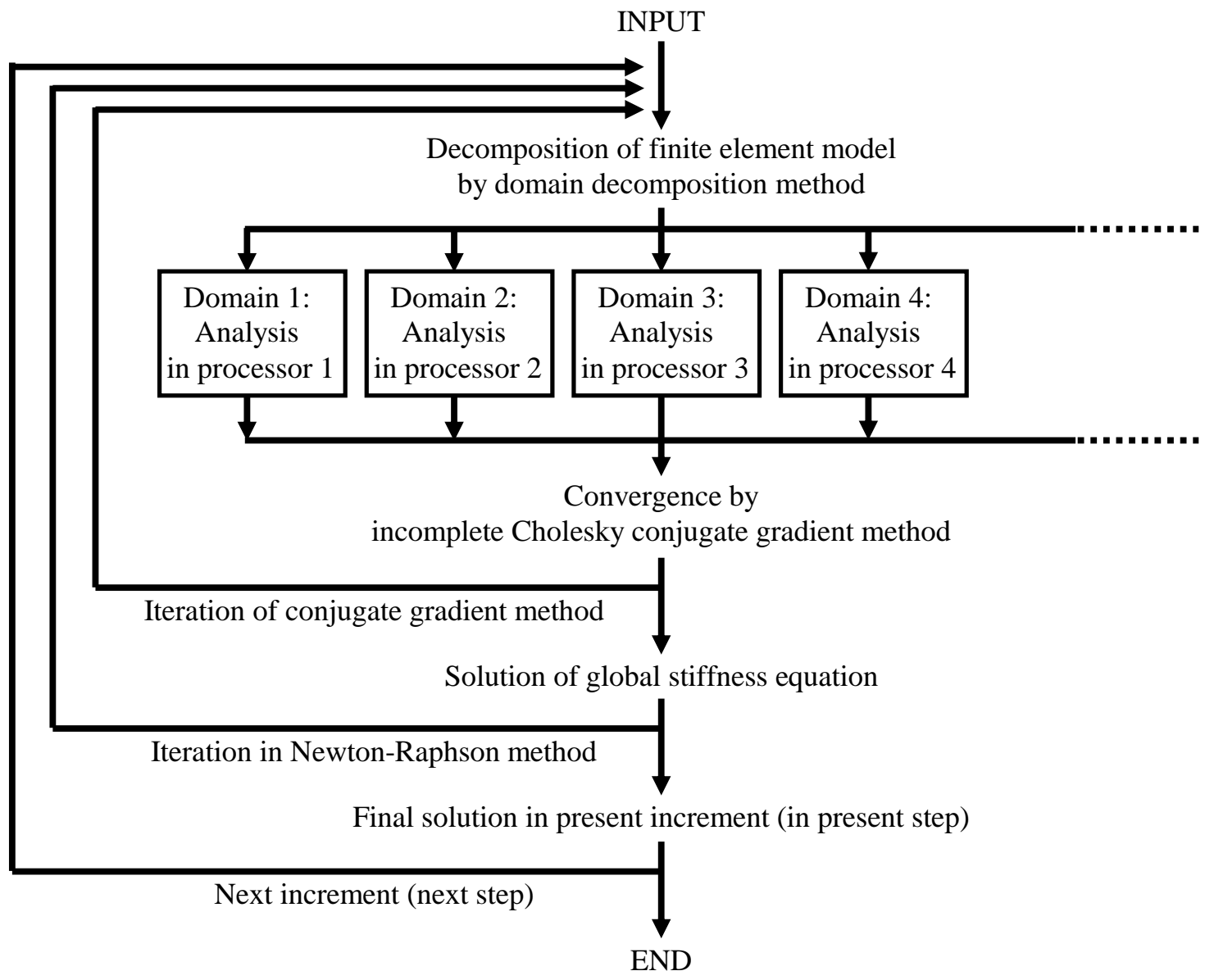

Figure 3. Flowchart of large-scale finite element analysis using domain decomposition method.

TABLE III. CALCULATION ENVIRONMENT.

\begin{tabular}{|l|c|}
\hline CPU & Intel core i7-3930K \\
\hline Number of cores and threads & 6 cores 12 threads \\
\hline Memory & $32 \mathrm{~GB}$ \\
\hline Harddisk & $1 \mathrm{~TB}$ \\
\hline Number of computer & 14 \\
\hline Total number of logical processors & 168 \\
\hline Calculation time & Fortran \\
\hline Programing language & 1440 hours 60 days $)$ \\
\hline
\end{tabular}

conducted by the arc-length method. In the initial increment, the average applied strain to the material in $\mathrm{x}$ direction is set to $0.004 \%$. The analysis is conducted until the average applied strain $6.0 \%$.

In this analysis, fourteen computers are connected. Each computer has six cores and twelve threads, and a total of 168 logical processors are unified to execute one calculation. The calculation is conducted continuously in 1440 hours. For the purpose of parallel computing, the domain decomposition method is applied, and for preconditioned conjugate gradient algorithm, incomplete Cholesky conjugate gradient method is applied. The numerical procedure of the analysis is shown in Fig. 3. The global finite element model representing the entire composite laminate which has complex internal structure including fibers and matrix is divided into domains, and the data of each domain is sent to each logical processor through communication between computers, and the calculation is executed in each logical processor. The calculation in each logical processor is independently conducted, and the convergence calculation is necessary to obtain the solution of the global finite element model. In order to improve the convergence calculation in the analysis, incomplete Cholesky conjugate gradient method is applied which results in increase of the calculation speed and reduction of calculation time in each one increment. The incomplete Cholesky decomposition is for the preconditioning of the conjugate gradient algorithm and for the purpose of the improvement of the convergence in the numerical analysis. The domain decomposition and the convergence calculation is conducted in each iteration and each increment in the nonlinear finite element analysis, 


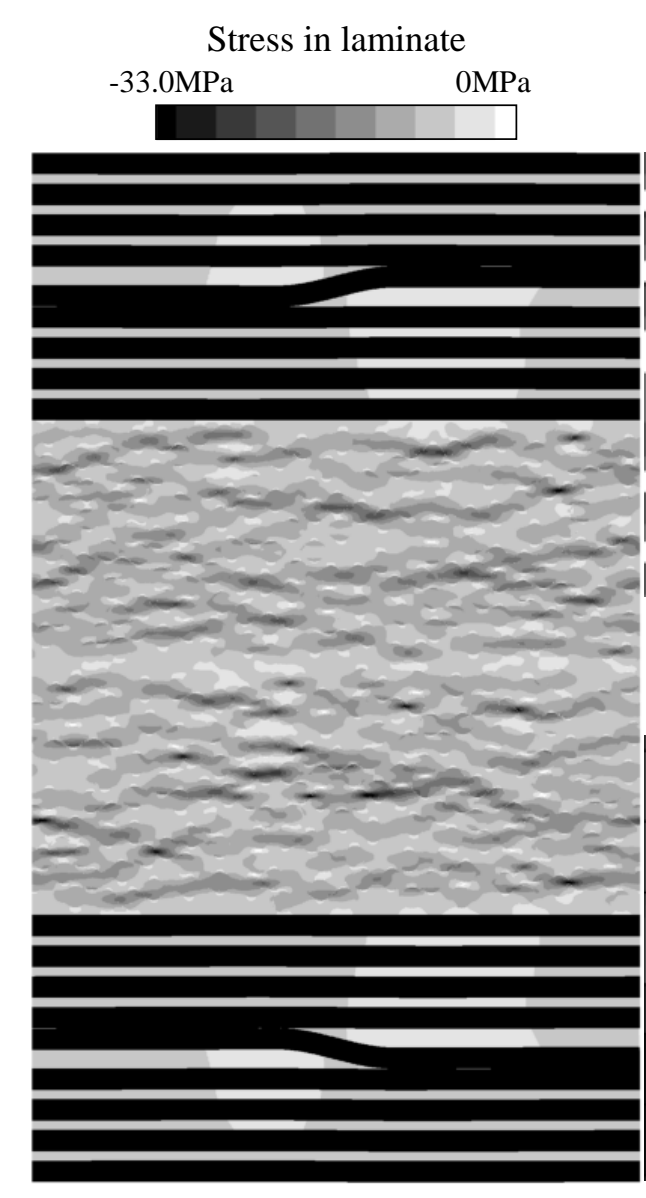

Stress in laminate
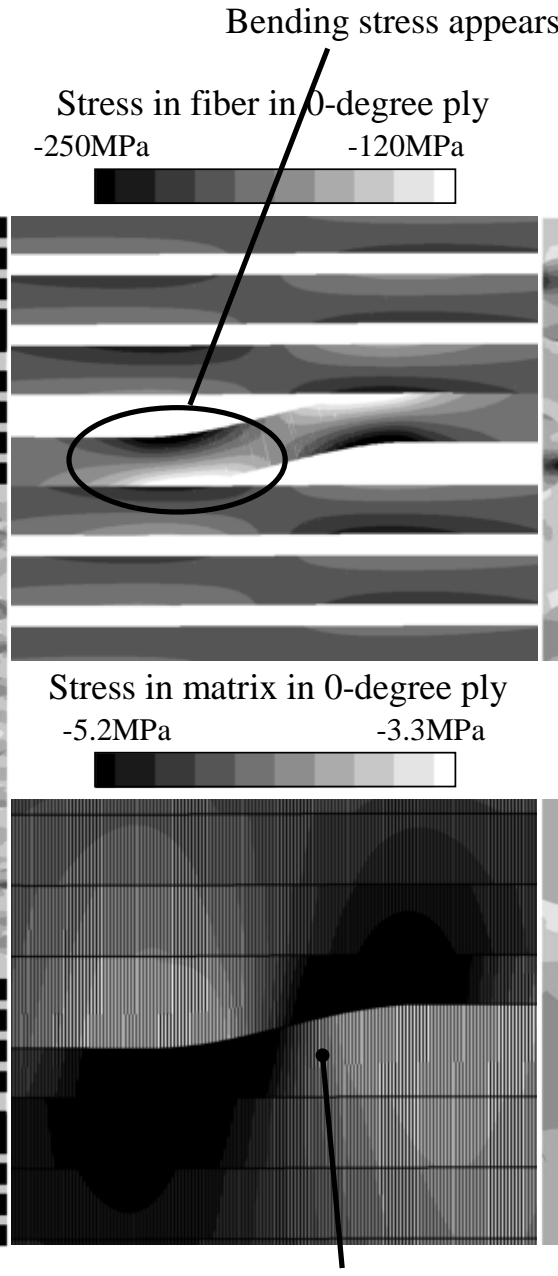

Stress concentration occurs in matrix.

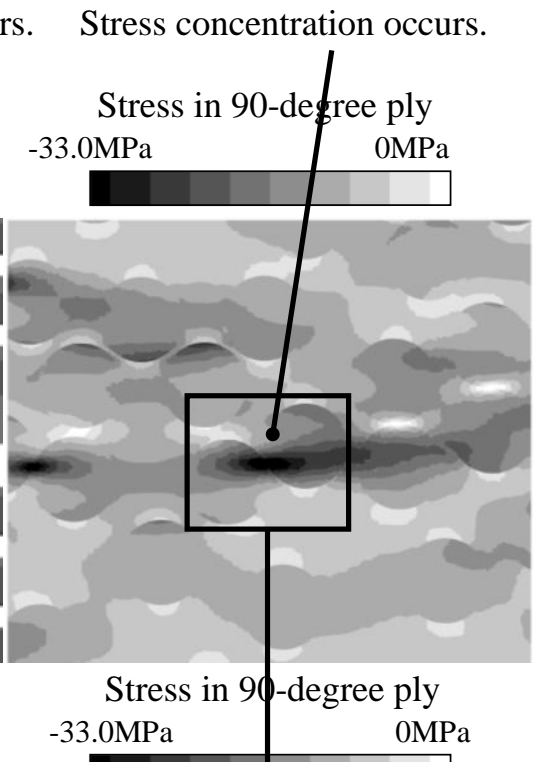

Figure 4. Simulated results of stress distribution at average applied strain $0.1 \%$.

and after the solution of the global finite element model is obtained, the numerical analysis is proceeded to the next iteration in Newton-Raphson iteration, and when the convergence in Newton-Raphson iteration is obtained, the numerical analysis is proceeded to the next increment. The analysis is proceeded until the final fracture is formed in the entire material. Table III summarizes the calculation environment in this analysis. The authors produced fortran program for this analysis, and the analysis is conducted using this program.

\section{SimUlated RESUltS AND DisCUSSIONS}

Fig. 4 shows the simulated results of stress distribution at average applied strain $0.1 \%$. In the laminated plate, particularly high stress distributes in reinforcement fibers in 0-degree plies, and a lot portion of the applied load to the laminate is supported by the fibers in 0-degree plies which are parallel to the loading direction. In the inside of 0-degree plies, stress disturbance occurs around the misalignment of fiber, and bending stress causes in the fiber which is increase of compressive stress in compressive deformation side and decrease of compressive stress in tensile deformation side, and the stress concentration occurs in matrix. In the inside of 90-degree plies, the stress concentration occurs in the material because of the randomness of the placement of fibers, and high stress appears in the area where fibers come close. When the applied load is increased, the stress state in matrix around the stress concentration area reaches the yield stress of matrix, and the yielding of matrix occurs in the local regions. Fig. 5 shows the simulated results of deformation at applied strain $0.1 \%$ and $4.3 \%$. At strain $0.1 \%$, the deformation of the laminate is close to the homogeneous compressive deformation, and the stress state in the material is close to the linear elastic state. At strain $4.3 \%$, the damage is formed in the laminate. In the simulated results, at strain $1.20 \%$ the damage initiates in the laminate, and after this point the damage develops in the laminate.

Fig. 6 shows the close-up view of the damage formed in the material. Fibers cause fracture because of the microscopic bending, and matrix causes shear deformation. The simulated damage is close to the microscope picture of the actual composite materials obtained in the experiment The current simulation is considered to correspond with the actual material deformation. Fig. 7 shows the simulated results of stress distribution in fibers and matrix with the deformation at strain $0.1 \%$ and $4.3 \%$. After the damage is formed in the material, high stress distributes in both fibers and matrix. 


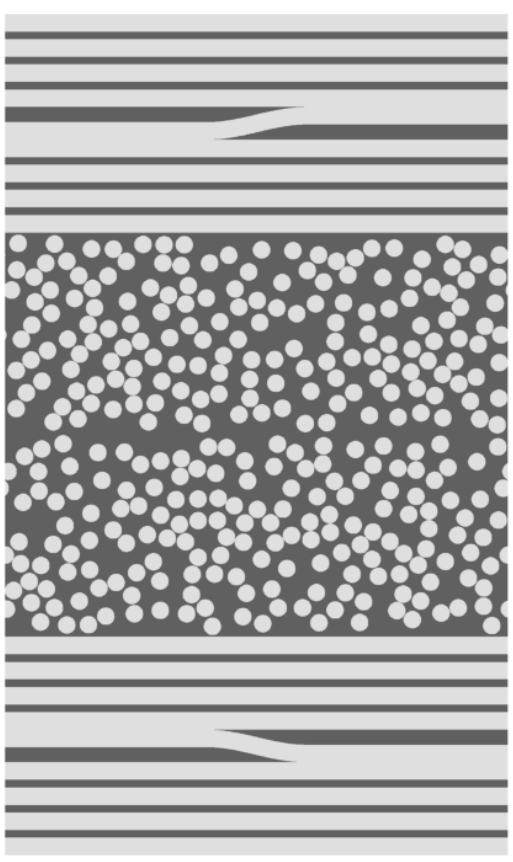

Applied strain $0.1 \%$

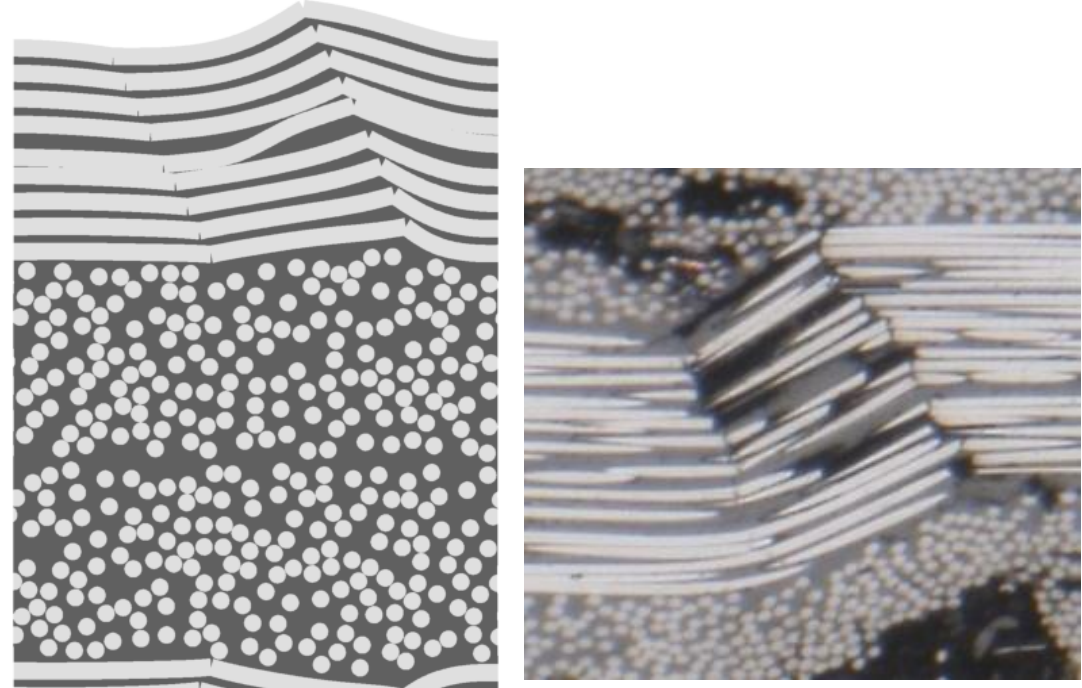

Experimental

(Microscope picture)

Figure 5. Simulated results of deformation before and after damage formation.

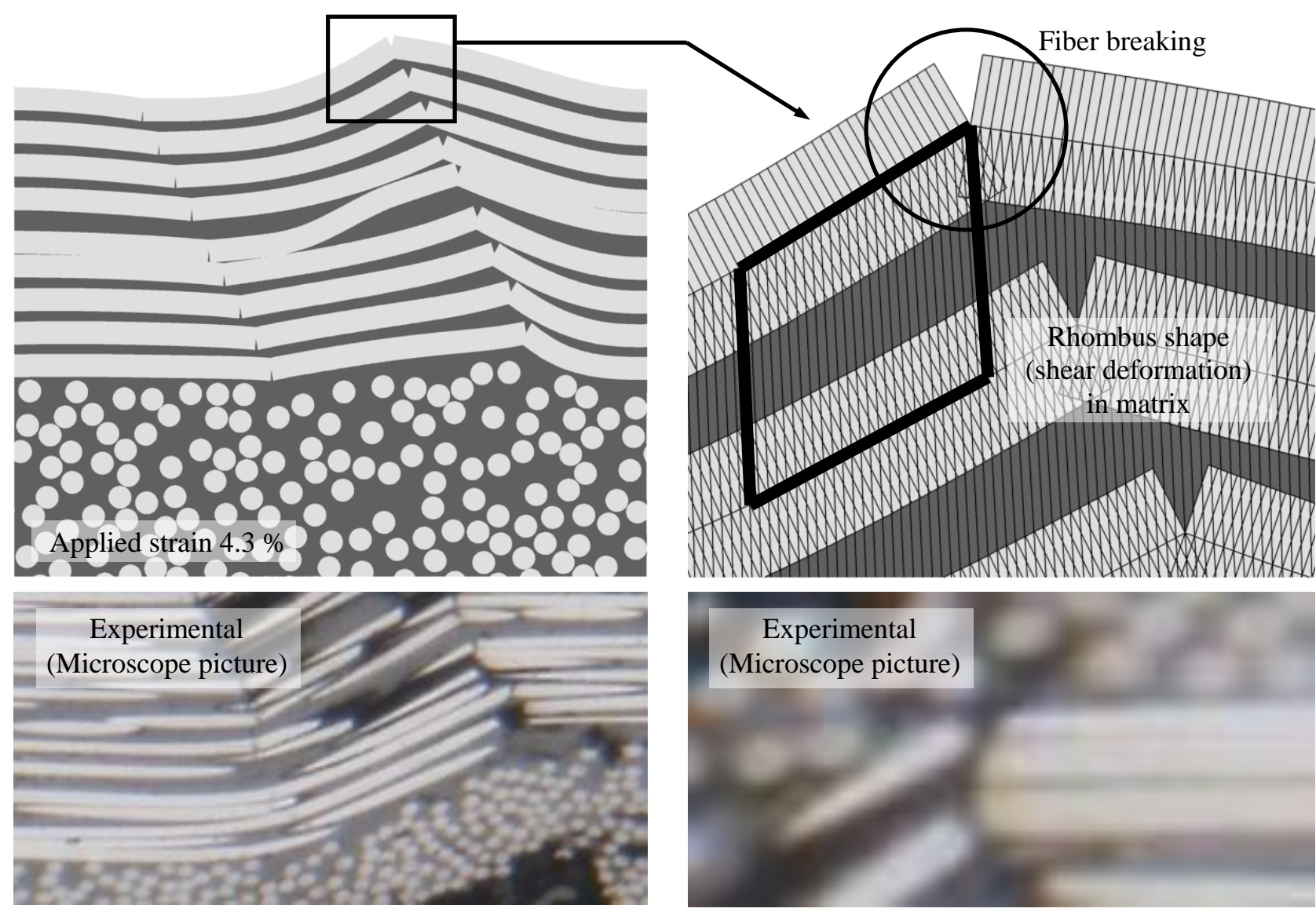

Figure 6. Simulated results of deformation after damage initiation. 
Deformation

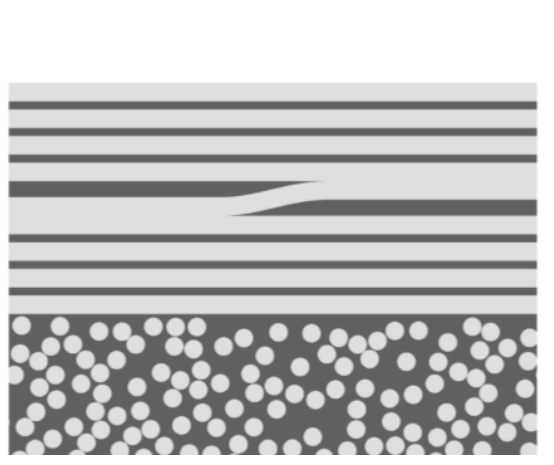

Deformation

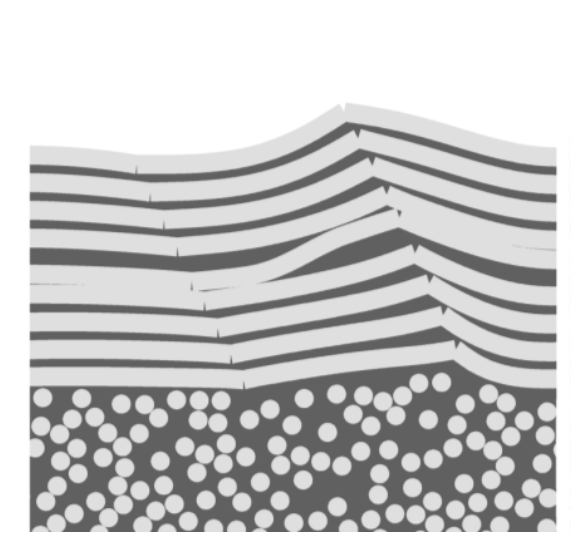

Stress in fiber

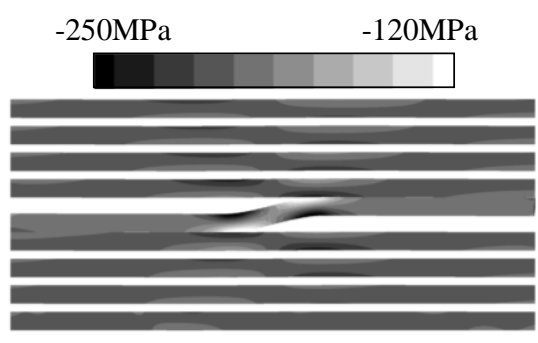

Average applied strain $0.1 \%$ Stress in fiber

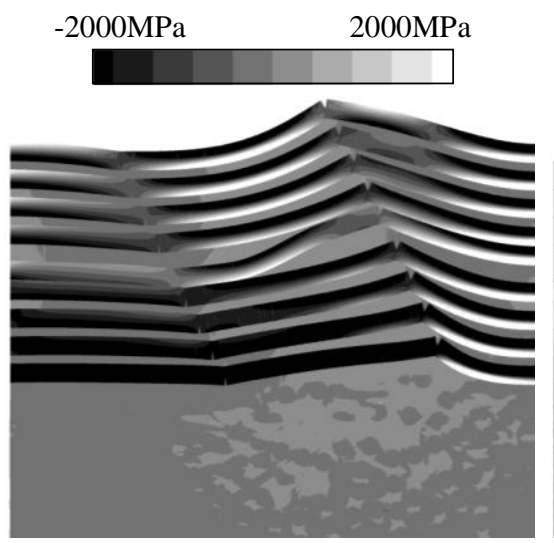

Average applied strain $4.3 \%$

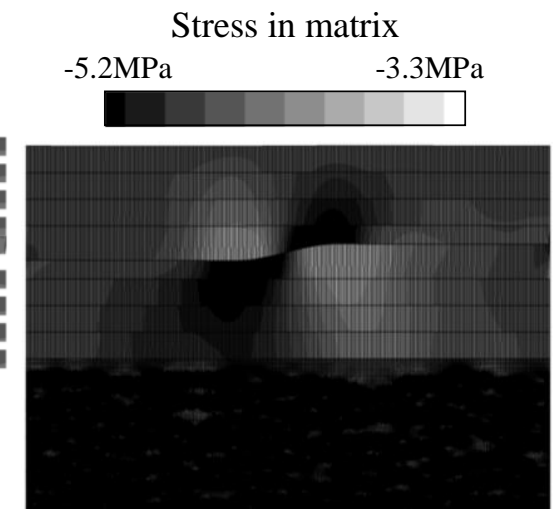

Stress in matrix

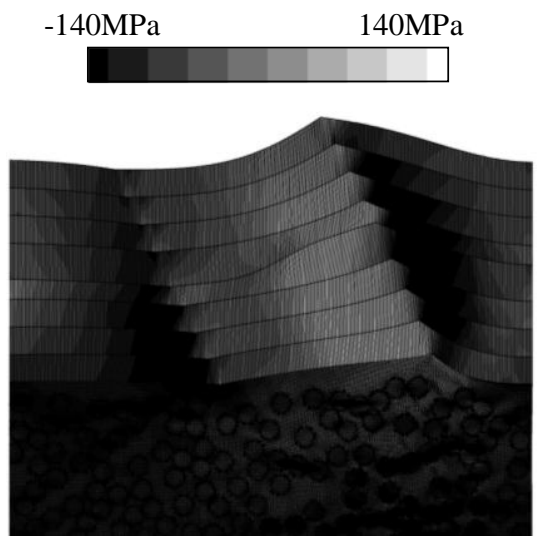

Figure 7. Simulated results of stress distribution before and after damage formation.

\section{CONCLUSIONS}

This study investigated the preparation for supercomputing of numerical simulation of fracture process of composite materials. The following remarks are obtained.

1. The reinforcement fibers in 0-degree plies are modeled by circle cross-section beam elements, and the cohesive elements are inserted in the connection of beam elements. The microscopic fiber bending and breaking are successfully simulated in the numerical analysis.

2. The domain decomposition method is applied for the purpose of parallel computing, and incomplete Cholesky conjugate gradient method is applied for pre-conditioned conjugate gradient algorithm. The numerical analysis is successfully distributed to multiple processors, and the speed of numerical calculation is improved, and the large-scale model is enabled to be analyzed.

3. The simulated results show that in the initial state of the loading, the stress concentration occurs around the initial misalignment of fiber in 0-degree plies, and it also occurs around the area where fibers come close in 90-degree plies. At average applied strain $1.20 \%$, the fiber breaking damage initiates in 0-degree plies, and after this point the damage develops in the material. The simulated damage is close to the microscope picture of the actual composite materials obtained in the experiment. The current simulation is considered to correspond with the actual material deformation.

\section{REFERENCES}

[1] M. J. Hinton and P. D. Soden, "Predicting Failure in Composite Laminates: The Background to The Exercise," Compos. Sci. Technol., vol. 58, pp. 1001-1010, 1998.

[2] C. R. Schultheisz and A. M. Waas, "Compressive Failure of Composites, Part I: Testing and Micromechanical Theories," Prog. Aerosp. Sci., vol. 32, pp. 1-42, 1996.

[3] A. M. Waas and C. R. Schultheisz, "Compressive Failure of Composites, Part II., Experimental Studies" Prog. Aerosp. Sci., vol. 32, pp. 43-78, 1996.

[4] S. T. Pinho, C. G. Davila, P. P. Camanho, L. Iannucci and P. Robinson, "Failure Models and Criteria for FRP under In-plane or Three-dimensional Stress States Including Shear Non-linearity," NASA Technical Memorandum-2005-213530, 2005.

[5] S. Basu, A. M. Waas, and D. R. Ambur, "Compressive Failure of Fiber Composites Under Multi-axial Loading," J. Mech. Phys. Solids, vol. 54, pp. 611-634, 2006.

[6] J. LLorca, C. González, J. M. Molina-Aldareguía, J. Segurado, R Seltzer, F. Sket, M. Rodríguez, S. Sádaba, R. Muñoz, and L. P. Canal, "Multiscale Modeling of Composite Materials: a Roadmap Towards Virtual Testing," Adv. Mater., vol. 23, pp. 5130-5147, 2011.

[7] E. Totry, C. Gonzalez, and J. LLorca, "Failure Locus of FiberReinforced Composites Under Transverse Compression and Outof-plane Shear," Compos. Sci. Technol., vol. 68, pp. 829-839, 2008.

[8] E. Totry, C. Gonzalez, and J. LLorca, "Prediction of the failure locus of C/PEEK composites under transverse compression and longitudinal shear through computational micromechanics," Compos. Sci. Technol., vol. 68, pp. 3128-3136, 2008. 
[9] E. Totry, C. Gonzalez, and J. LLorca, "Influence of the loading path on the strength of fiber-reinforced composites subjected to transverse compression and shear,” Int. J. Solids Struct., vol. 45, pp. 1663-1675, 2008.
[10] P. D. Soden, M. J. Hinton, and A. S. Kaddour, "Lamina Properties, Lay-up Configurations and Loading Conditions for a Range of Fibre-Reinforced Composite Laminates," Compos. Sci. Technol., vol. 58, pp. 1011-1022, 1998. 